tion. On Monday last a lecture on Chemistry in Reconstruction was given by Sir William Tilden, and vesterday Prof. W. H. Bragg lectured on Sound under Water and its Applications. The following lectures will be delivered at $5.30 \mathrm{on}$ the dates named:-July $x I$, Coal Conservation, Prof. H. E. Armstrong; July 14, Progress in Range-finders, Prof. Archibald Barr; July I8, Explosives, J. Young; July $2 \mathrm{I}$, Progress in Aviation during the War Period, L. Bairstow; July 23, How the Cotton Plant Feeds as well as Clothes Us, S. E. de Segundo; July 25 (6 p.m.), A Few Thoughts on the Development of London, Raymond Unwin; and July 28, Scientific Lighting and Industrial Efficiency, L. Gaster.

\section{STRONG ELECTROLYTES AND} IONISATION.

$\mathrm{T}$ is well known that the behaviour of strong electro. 1 lytes is very difficult to reconcile with the usually accepted theory of ionisation, in that the change of the degree of ionisation with the concentration is completely at variance with the requirements of the law of mass action. The abnormality of this very important group of substances is discussed in a series of papers by J. C. Ghosh (Journ. Chem. Soc., IgI8, vol. cxiii., pp. $449,627,707,790)$, who contends that the fundamental idea underlying the Arrhenius theory is not applicable to strong electrolytes. In place of this theory the author puts forward the view that the strong electrolytes are completely ionised, and that there is no question of the existence of non-ionised molecules in the usually accepted sense. The relations between the ions are controlled by the electrical forces, the magnitude of which corresponds with a certain potential which is characteristic of a given solution of an electrolyte. This potential affords a measure of the work which is required to free the ions from the influence of their mutual forces. Kinetic considerations suggest that the ions become "free" when their velocity exceeds a certain critical value, the fraction of the ions in this condition at any moment being shown by the ratio of the conductivity of the electrolvte in the given solution to the conductivity at infinite dilution. Assuming that the marshalling of the ions in solution corresponds with the arrangement of the atoms in the crystallised electrolyte, the author derives an expression for the characteristic potential in terms of the ionic charge, the dielectric constant of the medium, and the dilution of the solution. By introducing the Clausius virial theorem, the connection between the proportion of free ions and the osmotic ratio is deduced, and this relation differs notably from the well-known equation based on the Arrhenius theory. Experimental data relative to the influence of concentration, temperature, and solvent on the conducting power of strong electrolvtes are shown to be in accord with the author's hipothesis, which is developed in the last papor of the series so as to account for the abnormally hioh speeds of the hydrogen and hydroxvl ions, for which no satisfactory explanation has yet been given.

\section{THE FISHERIES AND THE INTER- NATIONAL COUNCIL. ${ }^{1}$}

II.

WE now come to the consideration of the hydrographical, meteorological, and physical work of the International Council in relation to the fisheries nroblems put before it. Out of a total of seventy fascicules of the "Publications de Circonstance," no

1 From a lecture givan in Aberdeen on March 4 by Prof. McIntosh, F.R.S. Continued from p. 258 .

No. 2593 , VOL. $\left.\mathrm{IO}_{3}\right]$ fewer than thirty-one belong to this section, and this in an inquiry specially devoted to the food-fishes. Besides, there is a great bulk of large quarto hydrographic and planktonic volumes which far exceeds anything else in the Council's publications. The special value of these to hydrographers does not concern the present criticism, but considerable dubiety surrounds the attempt to connect, for instance, oceanic currents with the eggs, larvæ, and young of the fishes, especially when, in their own words, such gives "some notion of how very complicated the question of the passive movements of the pelagic stages under the influence of the currents really is, and how it assumes a different form in each species." This view takes for granted that the larve and young are as passive as the eggs-a supposition dealt with long ago. Secondly, in other words, there are special currents which keep and carry the eggs and larvæ of the haddock annually to deep water, and others which bear with unfailing regularity the young cod shorewards; likewise others, with similar annual rhythm, sweep the larval and post-larval frog-fishes from their floating ribands of gelatinous mucus to deep water, along with such vagrant larvæ of the skulpin as have been hatched near the shore; still others which take the young plaice during the change of the eye to the beach. and. with nice discrimination, leave the long rough dabs and a number of dabs in deep wate: in the neighbourhood of their birthplace.

It would be interesting to inquire for the special currents which distribute the young of the viviparous Norway haddock in the open water, or for those which pass by the young of the viviparous blenny in the rock-pools, or, by ivav of varietv, for those motionless waters which leave the young herrings, like a carpet of threads, over square miles of the inshore waters, and for those special currents which invariably plant the young wolf-fishes, after their escape from the huge masses of large adhesive eggs, on rough ground. The hydrographers have, moreover, overlooked the "currents" which carry fishes and invertebrates hatched on the bottom to the surface of the water. and those, when they are older, which carry them down again. They have missed those discerning currents which, in the case of the ubiquitous pelagic eggs of the rocklings, convey some shorewards and send others to the deeper water. Moreover, they have forgotten the variable action of the winds in modifyins the currents.

Briefly, each species would thus appear to have a current to itself and adapted to its special needs-a supposition which cannot be accepted. The case of the North Sea Bank is given, in illustration, as a spawning are from which the small larvæ are distributed over the whole deep part of the Skagerak, the Norwegian channel and sea. It is stated that "tvpical tidal movements have been demonstrated in the North Sea, the resultant movement of which is often different in the different depths. This might possiblv be suffi. cient to separate the eggs in one laver from those in the nther. For the rest, this disposition is naturally very different in the different parts of the North Sea." Such uncertain oroping for an anchorage of an imnortant science in the fisheries is unworthy of it Support is drawn by the Council from Johs. Schmidt's observations in Iceland, already mentioned, but these might readilv be interpreted otherwise. An interestins local case, however, is that of the Atlantic current in the Baltic Sea, where it forms an intermediate one between the ton and the brttom. and. it is said, the eggs of plaice have alone been found in it as far as Bornholme. The adults pass higher un. but it is suggested that they come back to spawn there. These observations would require confirmation, and, in any case, cannot hold for the plaice of the North Sea 